\title{
Genetic and nongenetic profiling of milk pregnancy- associated glycoproteins in Holstein cattle
}

\author{
D. J. A. Santos, ${ }^{\star} †$ J. B. Cole,‡ D. J. Null, $\ddagger$ T. M. Byrem, $\S$ and L. Ma*1 \\ *Department of Animal and Avian Sciences, University of Maryland, College Park 20742 \\ †Departamento de Zootecinia, Universidade Estadual Paulista, Jaboticabal, 14884-900, Brazil \\ †Henry A. Wallace Beltsville Agricultural Research Center, Animal Genomics and Improvement Laboratory, Agricultural Research Service, USDA, \\ Beltsville, MD 20705-2350 \\ §Antel BioSystems Inc., Lansing, MI 48910
}

ABSTRACT

Pregnancy-associated glycoproteins (PAG) are secreted by the trophoblast and are detectable in maternal circulation around the time of attachment of the fetal placenta, as well as in blood and milk throughout gestation. The understanding of the genetic mechanisms controlling PAG levels can confer advantages for livestock breeding programs given the precocity and the ease of obtaining this phenotype from routine pregnancy diagnosis. The aim of this study was to characterize PAG levels by estimating genetic parameters and correlations with other dairy traits, and to identify genomic regions and candidate genes associated with PAG levels in milk. The PAG data consisted of pregnancy diagnoses using commercial assays from 2012 to 2017, and genotype data consisted of 54,123 SNP markers for 2,352 individuals (embryos and dams). The model included contemporary group (herd, year, and season) and embryo age as fixed effects, and random embryonic (direct) and maternal (indirect) genetic effects. Using genomic data, the estimated heritability for direct and maternal genetic effects ( \pm standard deviations) were $0.23 \pm 0.05$ and $0.11 \pm 0.05$, respectively. The genetic correlation between these effects was almost zero (0.001 $\pm 0.06)$. A preliminary analysis revealed low correlations between milk PAG levels and other dairy traits. The genome-wide association analysis was performed using 2 approaches: single-marker and single-step using all markers. Four genomic regions with direct genetic effects were detected on Bos taurus autosome (BTA) 6, BTA7, BTA19, and BTA29 of the embryonic genome. The BTA29 locus was within the bovine PAG gene cluster, suggesting a cis-regulatory quantitative

Received March 3, 2018.

Accepted July 23, 2018.

${ }^{1}$ Corresponding author: lima@umd.edu trait locus on the PAG expression. However, other associations, without an obvious link to PAG expression, could be related to the transportation of PAG and their concentration in milk. Only 1 region from the maternal genome, on BTA4, had a significant indirect effect, where WNT2 is a candidate gene related to placenta vascularization and gestation health. Collectively, our results suggest a moderate genetic control of milk PAG levels from both maternal and fetal genomes, but larger studies are needed to fully evaluate the usefulness of milk PAG in the genetic evaluation of fetal growth and cow fertility.

Key words: gestation, embryonic development, genomic analysis, genetic parameter, pregnancyassociated glycoprotein

\section{INTRODUCTION}

Pregnancy-associated glycoproteins (PAG) are secreted by the trophoblast cells of the placenta and are detectable in the maternal circulation around the time of attachment of the fetal placenta (3rd week in cattle), as well as in blood and milk throughout gestation (Zoli et al., 1992b; Friedrich and Holtz, 2010; Commun et al., 2016). The function of PAG is largely unclear; however, some studies have indicated a potential role in placental development, pregnancy maintenance, embryo survival, proteolytic activity, and immune modulation (Dosogne et al., 2002; Telugu et al., 2010; Pohler et al., 2013).

Whereas PAG are commonly used as early pregnancy biomarkers in ruminants, their quantification in the dam's circulation can also be considered as one of the earliest and easily detectable quantitative traits (López-Gatius et al., 2007). During pregnancy, the PAG protein is coded and regulated by the embryonic genome, but maternal resources and environments (Zoli et al., 1992a) can also affect the PAG level in the cow's circulation. Traits expressed early in life are of great importance for livestock-breeding programs because 
they can be used as selection criteria for economically important traits that are expressed later in life, which can accelerate genetic progress (Bourdon, 2000). Many reports in different species have suggested that altered fetal growth is associated with differences in postnatal growth and performance (Wu et al., 2006; Roland et al., 2012). Therefore, given the potential role of PAG on embryonic development and growth, PAG level may serve as an important early indicator of adult performance in ruminant species (Mercadante et al., 2013, 2016).

Genome-wide association studies (GWAS) have been successfully used to identify genetic variants associated with complex traits and diseases in humans and animals (Cole et al., 2011; Welter et al., 2014). More recently, GWAS has been extended from regular phenotypes to intermediate genomic phenotypes that are more closely related to DNA, including gene expression, methylation, and protein levels (Gilad et al., 2008; Albert et al., 2014; Hannon et al., 2016). A genetic study of PAG expression will provide useful information on the genetic architecture of protein expression. In addition, understanding the genetic mechanisms underlying PAG levels can also confer advantages for animal-breeding programs given the ease of obtaining this phenotype from routine pregnancy diagnosis.

The IDEXX Milk Pregnancy Test (IDEXX, Westbrook, ME) is a commonly used assay designed to detect PAG in bovine milk as a marker for pregnancy. The dairy industry has accumulated large amounts of milk PAG data using this pregnancy test. Despite the availability of milk PAG data from the dairy industry, limited reports exists in the literature on the heritability of PAG levels, their genetic correlation with other traits of economic importance, and genes or genetic variants associated with PAG levels. With the large amount of PAG and genotype data generated from the dairy industry, the aim of our study was to comprehensively characterize milk PAG levels using pedigree and genomic approaches, to genetically correlate PAG levels with important dairy traits, and to identify protein QTL regulating PAG levels using GWAS analyses of both maternal and embryonic genotypes.

\section{MATERIALS AND METHODS}

\section{PAG Data}

The PAG data used in our study were provided by Antel BioSystems (Lansing, MI) and were merged with animal identification and pedigree information in the National Dairy Database maintained by the Council on
Table 1. Summary statistics of pregnancy-associated glycoproteins (PAG) values by 2 diagnostic categories

\begin{tabular}{lcl}
\hline Category & Mean & Variance \\
\hline Open & $0.02^{\mathrm{a}}$ & $0.001^{\mathrm{a}}$ \\
Pregnant & $1.74^{\mathrm{b}}$ & $1.05^{\mathrm{b}}$ \\
Recheck & $0.17^{\mathrm{c}}$ & $0.002^{\mathrm{c}}$ \\
\hline
\end{tabular}

$\overline{{ }^{a-c} \text { Different letters refer to values statistically different with Tukey }}$ test $P$-value $<2.2 \times 10^{-16}$ or Bartlett test of homogeneity of variances $P$-value $<2.2 \times 10^{-16}$.

Dairy Cattle Breeding (Bowie, MD). All cow pregnancy diagnoses based on milk PAG concentrations were collected using the IDEXX Milk Pregnancy Test from 2012 to 2017. The original raw data set consisted of 225,006 pregnancy test records. Three categories of pregnancy diagnosis were reported based on PAG levels in milk: open, pregnant, and recheck. An exploratory analysis showed that PAG levels differ significantly between the 3 categories (Table 1 and Figure 1). As cows in the other 2 pregnancy categories had PAG levels close to zero, we only used pregnant cows for all subsequent analyses. The number of cows with repeated PAG records for the same pregnancy was low and only the first record for each parity was used. After merging PAG data with the National Dairy Database, we identified a total of 8,266 Holstein and 140 Jersey cows, and only the Holstein data were included for our analyses.

\section{Genotype Data}

The placenta has the same genome as the embryo. Because the placenta or embryo has a major genetic contribution to the expression of PAG, we sought to identify as many as possible the genotyped embryos from the PAG data. When available, the dam genotype could also be included to evaluate their relative contributions to the genetic variation of PAG levels. For each pregnant cow with PAG levels measured, we identified the fetus based on pedigree and birth date information, assuming a gestation length of $\sim 283 \mathrm{~d}$. Briefly, the fetus was obtained as the progeny of a cow born within $283 \mathrm{~d}$ after the PAG test date. Using this approach, the longest time between PAG test day and calving is $242 \mathrm{~d}$ in our data. Cows with multiple offspring born within the expected period were excluded. In the end, we identified 1,993 genotyped embryos in the National Dairy Genomics Database, for which 359 dams were also genotyped (Table 2). The genotype data were generated from 16 different SNP arrays with number of SNP ranging from $7 \mathrm{~K}$ to $50 \mathrm{~K}$. All individuals were imputed to a common panel of 60,671 SNP using FindHap version 3 (VanRaden et al., 2011). For 
Table 2. Summary statistics of the edited pregnancy-associated glycoproteins (PAG) data

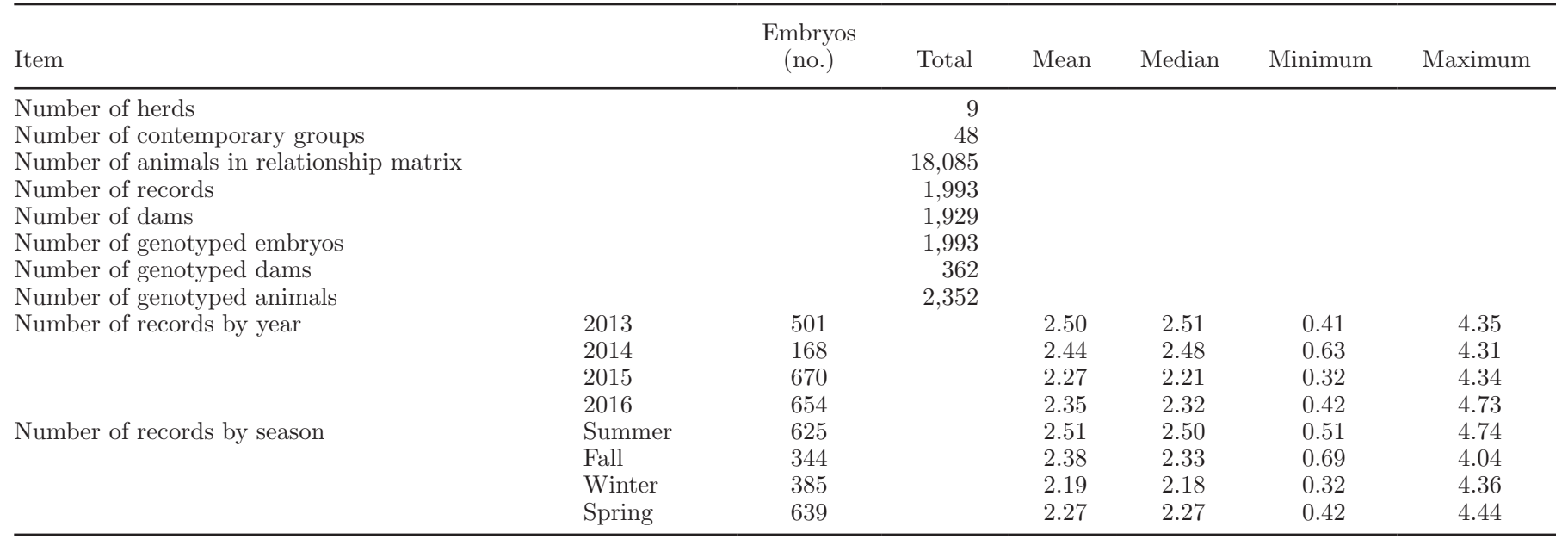

data editing, we retained those SNP with nonmissing rate $\geq 0.98$ and minor allelic frequency $\geq 0.05$. The final genotype data consisted of 54,123 SNP, including both autosomal and X-chromosome markers.

\section{Nongenetic Data}

Due to the extensive use of sexed semen in the dairy industry, only a few male embryos were observed in
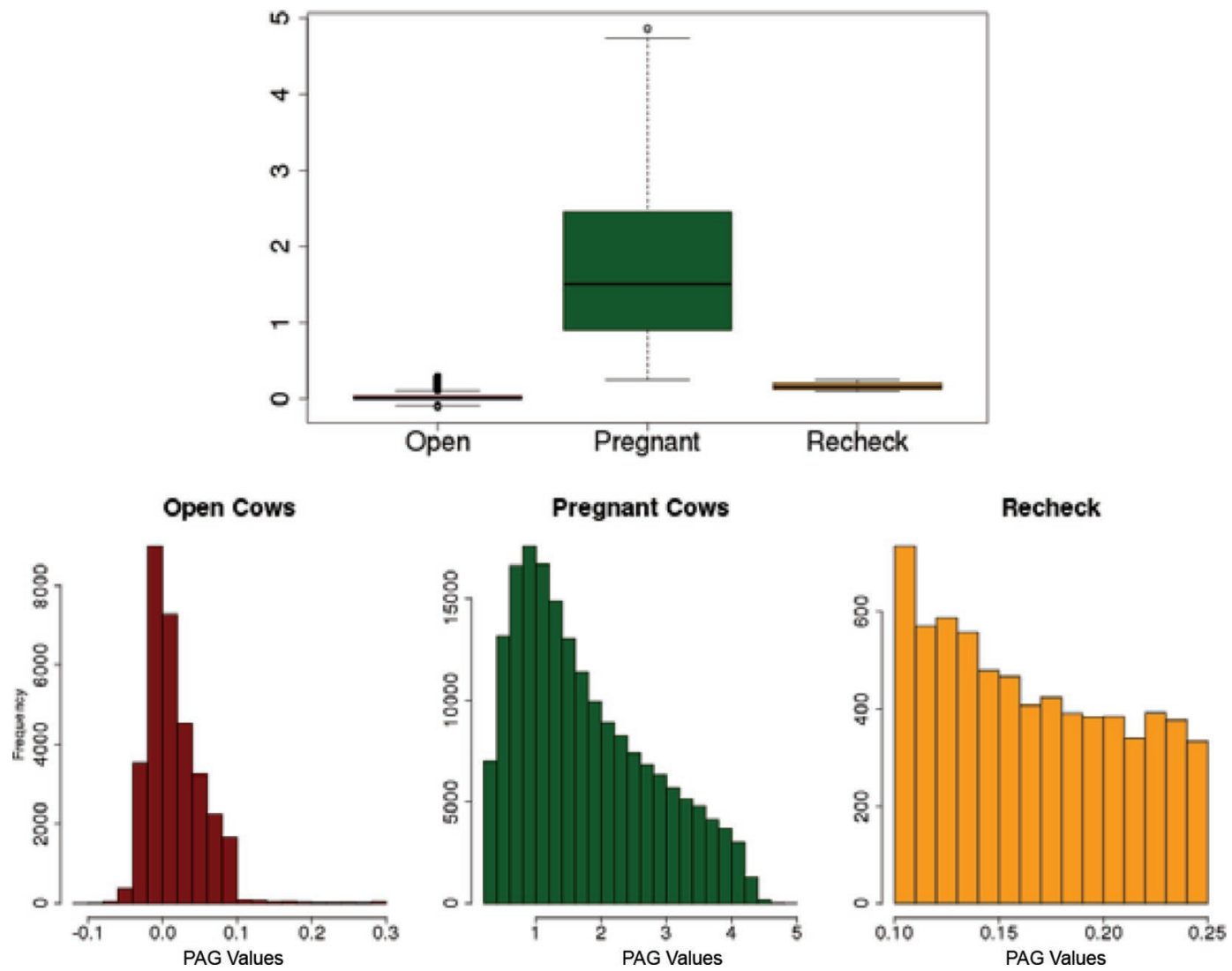

Figure 1. Distribution of milk pregnancy-associated glycoproteins (PAG) values by 3 diagnostic categories of pregnancy test. In the top panel, the boxes are defined by the 25 th and 75 th percentiles, midlines are the median, dots indicate outliers, and whiskers show the ranges after removing outliers. Color version available online. 
the final data set $(n=68)$. These male embryos were excluded to have a robust model without the sex effect but including the $\mathrm{X}$ chromosome. We fitted no maternal permanent environmental effect in the model because only a few dams had multiple gestations. Seasons of PAG test day were divided into 4 categories: summer (June to August), fall (September to November), winter (December to February), and spring (March to May). The contemporary group was defined as a combination of herd, year, and season. Contemporary groups with fewer than 5 animals were excluded and PAG values greater than 3 standard deviations of the mean of a contemporary group were discarded. The cow's age at the pregnancy test was computed from the birth date and PAG test date. The embryo's age was estimated from the PAG test date and the birth date of the fetus, assuming a gestation length of $283 \mathrm{~d}$. The data used in the analyses are described in Table 2 and Supplemental Figure S1 (https://doi.org/10.3168/ jds.2018-14682). Nongenetic effects were assessed using the aov function from the stats package of $\mathrm{R}$ version 3.4.3 (R Core Team, 2013). A linear model using the nlme package (Pinheiro, 2009) was fitted with all described fixed effects, and sire and dam as random effects.

\section{Estimation of Genetic Parameters}

Genetic parameters were obtained in a linear mixed model using the nongenetic effects, described above as fixed effects, and 2 structures of the random effects (embryonic/direct and maternal/indirect). Traditional and genomic models were used to evaluate the usefulness of genomic data in the study of PAG levels. The variance components were estimated using the restricted maximum likelihood (REML) method. The analysis was performed using BLUPF90 ver. 1.57 (Misztal et al., 2014). The general model can be described as

$$
\mathbf{y}=\mathbf{X b}+\mathbf{Z a}+\mathbf{W m}+\mathbf{e}
$$

where $\mathbf{y}$ is a vector of PAG values; $\mathbf{b}$, $\mathbf{a}$, and $\mathbf{m}$ are the solution vectors of fixed, direct and maternal genetic effects, respectively; $\mathbf{X}, \mathbf{Z}$, and $\mathbf{W}$ are incidence matrices relating phenotypes with solution vectors $\mathbf{b}$, $\mathbf{a}$, and $\mathbf{m}$, respectively; and $\mathbf{e}$ is a vector of residuals assuming $\mathbf{e} \sim N\left(0, \mathbf{I} \sigma_{\mathrm{e}}^{2}\right)$, where $\mathbf{I}$ is the identity matrix and $\sigma_{\mathrm{e}}^{2}$ is the residual variance. For direct and maternal effects, we used 2 variance structure models according to the relationship matrix and covariance between genetic effects:

$$
\begin{gathered}
\text { Traditional Model }=\operatorname{var}\left[\begin{array}{l}
a \\
m
\end{array}\right]=\left[\begin{array}{cc}
\sigma_{D}^{2} & \sigma_{D M} \\
\sigma_{D M} & \sigma_{M}^{2}
\end{array}\right] \otimes \mathbf{A}, \text { and } \\
\text { Genomic Model }=\operatorname{var}\left[\begin{array}{l}
a \\
m
\end{array}\right]=\left[\begin{array}{cc}
\sigma_{D}^{2} & \sigma_{D M} \\
\sigma_{D M} & \sigma_{M}^{2}
\end{array}\right] \otimes \mathbf{H},
\end{gathered}
$$

where $\mathbf{A}$ is the pedigree relationship matrix for 18,085 individuals, $\mathbf{H}$ is a matrix composed of $\mathbf{A}$ and $\mathbf{G}$ (the genomic relationship matrix of 2,353 individuals), and $\otimes$ is the direct (Kronecker) product between matrices, $\sigma_{D}$ is the direct genetic variance, $\sigma_{M}$ is the maternal genetic variance, and $\sigma_{D M}$ is the covariance between direct and maternal effects. The inverse of $\mathbf{H}$ matrix $\left(\mathbf{H}^{-1}\right)$ is constructed as

$$
\mathbf{H}^{-1}=\mathbf{A}^{-1}+\left[\begin{array}{cc}
0 & 0 \\
0 & \mathbf{G}^{-1}-\mathbf{A}_{22}^{-1}
\end{array}\right],
$$

where $\mathbf{G}^{-1}$ is the inverse of the genomic relationship matrix and $\mathbf{A}_{22}^{-1}$ is the inverse of the numerator relationship matrix of genotyped animals (Aguilar et al., 2010). The $\mathbf{G}$ matrix was calculated according to (VanRaden, 2008).

\section{Correlation with Economically Important Dairy Traits}

To evaluate the usefulness of PAG data in animalbreeding programs, we calculated the correlations between milk PAG levels and economically important dairy traits in a preliminary analysis. As the final edited PAG data closely followed a normal distribution (Supplemental Figure S1; https://doi.org/10.3168/jds .2018-14682), Pearson correlations were calculated between direct or maternal genetic effect of PAG with genomic breeding values (GEBV) or deregressed GEBV of 34 dairy traits from the National Dairy Database. The correlation between the direct genetic effect of PAG and other dairy traits approximately represents genetic correlation with future adult traits of the conceptus. The correlation using maternal genetic effects of PAG represents genetic correlation with dam traits (current). 


\section{GWAS}

We used 2 GWAS approaches: single-step GWAS (ssGWAS; Wang et al., 2012) and a mixed model method using the MMAP software (O'Connell, 2015). The first approach is based on the genomic model described above with the following steps:

(1) $\mathbf{D}=\mathrm{I}$

(2) $\mathbf{G}=\mathbf{Z}_{\mathbf{m}} \mathbf{D} \mathbf{Z}_{\mathbf{m}}{ }^{\prime}\left(\sum_{i=1}^{\mathbf{M}} 2 p_{i} q_{i}\right)^{-1}$, where $\mathbf{Z}_{\mathbf{m}}$ is the marker incidence matrix adjusted for allele frequency, and $p$ and $q$ are the frequencies of the reference and alternative alleles.

(3) The GEBV ( $\hat{a}$ or $\hat{m}$ ) are obtained and converted to SNP effects $(\hat{u})$ using $\mathbf{D Z}_{\mathbf{m}}{ }^{\prime}(\mathbf{G})^{-1}$ GEBV;

(4) The weight of the $i$ th SNP (the $i$ th element of $\mathbf{D}$ or $\left.d_{i}\right)$ is calculated as $d_{i}=\hat{u}_{\mathrm{i}}^{2} 2 p_{i} q_{i}$;

(5) Normalize SNP weights to have constant genetic variances of SNP effects; and

(6) Loop to step 2 twice and exit.

The results are reported as the proportion of variance explained by windows of 10 adjacent SNP, $\frac{\operatorname{Var}\left(\sum_{j=1}^{10} \mathbf{Z}_{j} \hat{u}_{j}\right)}{\sigma_{a}^{2}}$

The 10-SNP windows had an average

length of $437.6 \mathrm{~kb}$ in our data. In the mixed model GWAS using MMAP, the additive effect was divided into a random polygenic effect and a fixed effect of the candidate SNP. The variance components were estimated using REML. The model can be generally presented as

$$
\mathbf{y}=\mathbf{X b}+\mathbf{m} u+\mathbf{a}+\mathbf{e}
$$

where $\mathbf{y}, \mathbf{X}, \mathbf{b}$, and $\mathbf{e}$ are similar to those described in Equation 1, and $\mathbf{a} \sim N\left(0, \sigma_{a}^{2} \mathbf{G}\right)$ representing the polygenic effect; $\mathbf{m}=$ vector of the candidate SNP genotype (allelic dosage) for each animals, and $u=$ effect of a SNP. For each SNP, a Wald test was applied to evalu-

Table 3. Test of individual fixed effects on pregnancy-associated glycoprotein (PAG) levels

\begin{tabular}{lc}
\hline Source of variation & $P$-value \\
\hline Herd & $<2 \times 10^{-16}$ \\
Year & $8.1 \times 10^{-5}$ \\
Season & $3.1 \times 10^{-6}$ \\
Embryo/conceptus age & $<2 \times 10^{-16}$ \\
Dam age & 0.005 \\
\hline
\end{tabular}

ate the alternative hypothesis, $\mathrm{H}_{1}: u \neq 0$, against the null hypothesis, $\mathrm{H}_{0}: u=0$. Bonferroni correction for multiple comparisons was applied to control the type-I error rate.

Gene coordinates in the UMD v3.1 assembly (Zimin et al., 2009) were obtained from the Ensembl Genes 90 database using the BioMart tool (Kinsella et al., 2011). The cattle QTLdb database (Hu et al., 2013) was examined to check if any associated genomic region was previously reported as a cattle QTL. The linkage disequilibrium (LD) between SNP was calculate using the PLINK software (Purcell et al., 2007).

\section{RESULTS}

\section{Nongenetic Effects}

All nongenetic effects tested individually were significantly different from zero, including the 3 components used for defining contemporary groups (Table 3 and Supplemental Figure S2; https://doi.org/10.3168/jds .2018-14682). The most significant nongenetic effects were herd and embryo age. We observed a positive linear correlation between PAG levels and embryo age, with a moderate coefficient of determination value of 0.29 (Figure 2). Although the embryo age was potentially over estimated, ranging from 50 to $190 \mathrm{~d}$, our linear model analysis using embryo age as a covariate should be unaffected by this over estimation. Dam age had a less significant effect, with a positive trend and low coefficient of determination of 0.004 (Figure 2), so it was unadjusted in the genetic model. As the season effect was significant, we compared the PAG levels between the 4 season classes (Supplemental Table S1; https://doi.org/10.3168/jds.2018-14682). The highest PAG level was observed in summer and the lowest PAG production was seen in winter.

\section{Genetic Parameters}

As shown in Table 4, estimated heritability for direct embryonic effects varied from 0.15 based on pedigree data (traditional model) to 0.23 with pedigree plus genomic data (genomic model). The heritability for indirect maternal effect was about 0.11 regardless of whether pedigree or genomic relationship matrix was used. When comparing genomic data (genomic model) and pedigree data (traditional model), the estimated direct variance and heritability increased, indicating genomic data provided more information than pedigree data. The small difference between the 2 models from the maternal side may be in part due to the low number of genotyped cows analyzed. 
Table 4. Genetic parameters and standard errors estimated using traditional and genomic models ${ }^{1}$

\begin{tabular}{lccrcccc}
\hline Model & $\sigma_{d}^{2}$ & $\sigma_{m}^{2}$ & $\sigma_{d m}$ & $\sigma_{e}^{2}$ & $\sigma_{p}^{2}$ & $h_{d}^{2}$ \\
\hline Traditional & $0.07 \pm 0.03$ & $0.06 \pm 0.06$ & $-0.12 \pm 0.02$ & $0.34 \pm 0.03$ & $0.48 \pm 0.04$ & $0.15 \pm 0.06$ & $0.13 \pm 0.07$ \\
Genomic & $0.11 \pm 0.03$ & $0.05 \pm 0.03$ & $0.02 \pm 0.02$ & $0.31 \pm 0.02$ & $0.47 \pm 0.03$ & $0.23 \pm 0.05$ & $0.11 \pm 0.06$ \\
\hline
\end{tabular}

${ }^{1}$ Indices $d, m, e$, and $p$ designate direct, maternal, residual, and phenotypic components, respectively, for variances $\left(\sigma^{2}\right)$, covariance $(\sigma)$, and heritability $\left(h^{2}\right)$.

\section{Correlation Between PAG and 34 Dairy Traits}

Generally, we observed low correlations between PAG levels and dairy traits in this preliminary analysis. Table 5 showed the Pearson correlations calculated between PAG breeding values (direct or maternal) and 34 economically important dairy traits (original or deregressed GEBV). We observed similar correlations between PAG and net merit across the 4 combinations of breeding values, ranging from 0.09 to 0.12 . The PAG levels generally had positive correlation with production traits, including milk, fat, protein, fat percentage, and protein percentage. However, PAG levels had mostly negative correlation with reproduction traits, including daughter pregnancy rate, heifer conception rate, and cow conception rate. We observed mixed correlations (both positive and negative) between PAG and body conformation traits. The largest positive correlation was observed between rear leg (side) and maternal breeding values of PAG (0.26), whereas the largest negative correlation was between foot angle and maternal PAG ( -0.28 and -0.35$)$. Interestingly, SCS was positively correlated with both direct and maternal PAG effects, with a correlation coefficient greater than 0.1 . We also observed positive correlation between maternal PAG values and health-related traits, including livability and productive life.

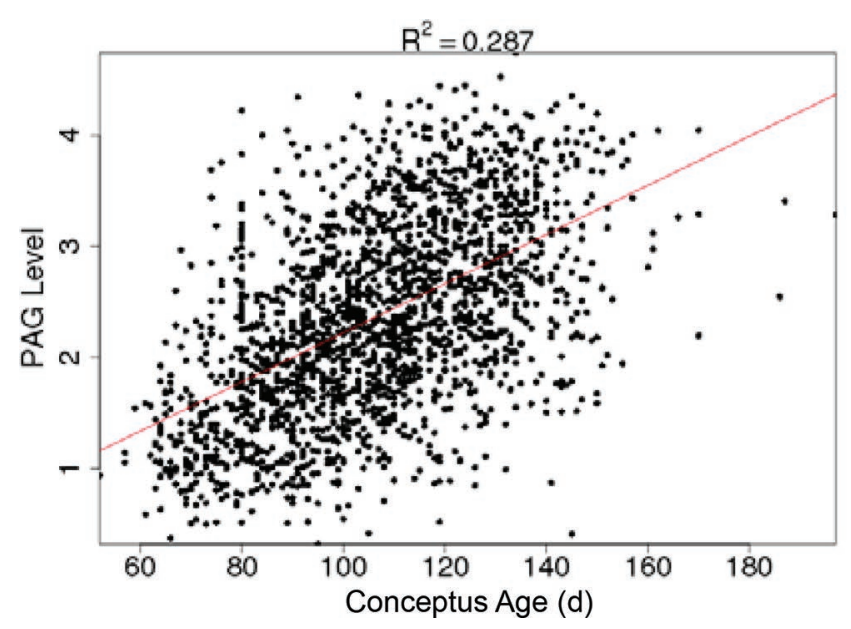

\section{GWAS}

We conducted GWAS of milk PAG levels using 2 approaches that generally provided consistent results: mixed model approach and ssGWAS. Because PAG expression in milk was coded by the embryo genome but affected by the maternal resources, we scanned both the embryonic and maternal chromosomes to identify candidate gene and genomic regions associated with milk PAG levels.

Direct Genetic Effects from the Embryo. In the embryonic genome, 4 genomic regions were detected on Bos taurus autosome (BTA) 6, BTA 7, BTA 19, and BTA 29 by the traditional mixed model GWAS after Bonferroni correction (Figure 3 and Table 6). The 2 most significant regions on BTA 19 and BTA 29 were also detected by ssGWAS as the top 2 regions explaining more than $0.4 \%$ direct genetic variance (Supplemental Figure S3; https://doi.org/10.3168/jds.2018-14682).

The BTA 29 region contains a cluster of over 13 bovine PAG genes from PAG2, PAG4, to PAG21 (Table 6 and Figure 4). As cis-regulating expression QTL have been well characterized in animals and humans, this association indicates the existence of a cis-regulating protein QTL of PAG expression and validates the quality of the current study. The most significant SNP in this region was ARS-BFGL-NGS-95362 $(P$-value $=5.3$

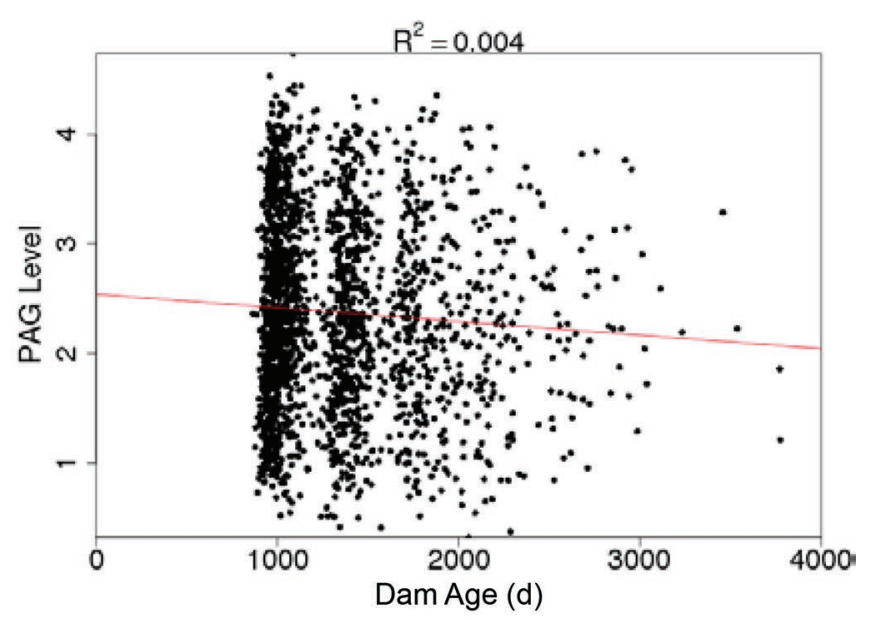

Figure 2. Pregnancy-associated glycoproteins (PAG) levels by embryo or conceptus age and dam age. Color version available online. 
Table 5. Correlation between pregnancy-associated glycoproteins (PAG) and 34 traditional dairy traits ${ }^{1}$

\begin{tabular}{|c|c|c|c|c|}
\hline \multirow[b]{2}{*}{ Trait } & \multicolumn{2}{|c|}{ Deregressed GEBV } & \multicolumn{2}{|c|}{ GEBV } \\
\hline & $\begin{array}{l}\text { PAG direct } \\
(\mathrm{n}=1,993)\end{array}$ & $\begin{array}{l}\text { PAG maternal } \\
\quad(\mathrm{n}=362)\end{array}$ & $\begin{array}{l}\text { PAG direct } \\
(\mathrm{n}=1,993)\end{array}$ & $\begin{array}{l}\text { PAG maternal } \\
\quad(\mathrm{n}=362)\end{array}$ \\
\hline Milk & $0.07^{*}$ & 0.05 & $0.06^{*}$ & 0.05 \\
\hline Fat & $0.17 * * *$ & 0.02 & $0.14^{* * *}$ & 0.06 \\
\hline Protein & $0.14 * * *$ & 0.07 & $0.15 * * *$ & $0.11^{*}$ \\
\hline Fat percent & $0.11 * * *$ & -0.02 & $0.06^{*}$ & 0.01 \\
\hline Protein percent & $0.13 * * *$ & 0.01 & $0.12 * * *$ & $0.06^{*}$ \\
\hline Sire calving ease & 0.04 & $0.11 * * *$ & 0.04 & 0.01 \\
\hline Daughter calving ease & -0.02 & $0.11^{*}$ & 0.04 & 0.05 \\
\hline Sire stillbirth & -0.01 & -0.10 & 0.02 & -0.05 \\
\hline Daughter stillbirth & -0.02 & 0.08 & -0.02 & 0.03 \\
\hline Net merit & $0.12^{* * *}$ & -0.01 & $0.09^{* * *}$ & 0.09 \\
\hline $\mathrm{SCC}$ & $0.05^{*}$ & $0.15^{* * *}$ & 0.11 & 0.12 \\
\hline Daughter pregnancy rate & -0.03 & $-0.20^{*}$ & $-0.04^{* * *}$ & $-0.12^{*}$ \\
\hline Heifer conception rate & 0.00 & -0.10 & 0.03 & -0.05 \\
\hline Cow conception rate & -0.01 & $-0.12^{*}$ & -0.02 & -0.02 \\
\hline Productive life & 0.02 & 0.00 & -0.02 & 0.07 \\
\hline Livability & $-0.09 *$ & $0.15 * * *$ & -0.06 & 0.15 \\
\hline Final score & 0.01 & -0.07 & 0.01 & -0.02 \\
\hline Stature & -0.04 & $-0.15^{*}$ & $-0.06^{*}$ & $-0.19^{*}$ \\
\hline Strength & $0.02 *$ & $-0.12^{*}$ & $0.02 *$ & $-0.16 * * *$ \\
\hline Dairy form & -0.02 & 0.09 & -0.01 & 0.06 \\
\hline Foot angle & $0.10^{*}$ & $-0.35 * * *$ & $0.06^{*}$ & -0.28 \\
\hline Rear legs (side) & $-0.15 * * *$ & $0.27 * * *$ & $-0.10^{*}$ & $0.26 * * *$ \\
\hline Body depth & -0.02 & -0.04 & 0.01 & $-0.12^{* * *}$ \\
\hline Rump angle & $-0.06^{*}$ & -0.02 & -0.08 & -0.11 \\
\hline Rump width & $0.07^{*}$ & 0.02 & 0.01 & -0.01 \\
\hline Fore udder attachment & $0.06^{*}$ & -0.03 & -0.01 & 0.03 \\
\hline Rear udder height & $0.05^{*}$ & -0.04 & 0.00 & 0.03 \\
\hline Udder depth & -0.02 & -0.05 & $-0.06^{*}$ & -0.04 \\
\hline Udder cleft & $-0.06^{*}$ & 0.21 & $-0.04^{*}$ & 0.15 \\
\hline Front teat placement & 0.00 & $0.24^{* * *}$ & -0.01 & $0.19^{*}$ \\
\hline Teat length & 0.00 & $-0.19 * * *$ & 0.00 & $-0.21 * * *$ \\
\hline Rear legs (rear) & 0.04 & $-0.22^{*}$ & $0.07^{*}$ & $-0.17 * * *$ \\
\hline Feet and legs & 0.01 & $-0.25^{*}$ & 0.02 & $-0.16^{*}$ \\
\hline Rear teat placement & 0.01 & $0.26^{*}$ & -0.02 & $0.18^{*}$ \\
\hline
\end{tabular}

$\left.\times 10^{-10}\right)$, which explained about $0.44 \%$ direct genetic variance (Supplemental Figure S3; https://doi.org/10 .3168/jds.2018-14682). In addition, the cattle QTLdb database reported 66 QTL in this region, and some of them are related to conception and pregnancy rates.

The most significant association was identified on BTA19, with the top SNP Hapmap39272-BTA-45334 $\left(P\right.$-value $\left.=2.4 \times 10^{-11}\right)$ explaining more than $0.56 \%$ direct genetic variance. This region contains 97 QTL for milk protein, gestation length, fertility, calving ease, and body conformation traits reported in the cattle QTLdb database; however, we found no obvious biological links between the genes near the top SNP and PAG expression in milk (Table 6).

For the BTA7 region, the SNP with the strongest association was ARS-BFGL-NGS-115315 ( $P$-value $=$ $\left.6.5 \times 10^{-8}\right)$. In this region, 134 QTL were previously reported to be related to conception rate, calving ease, and conformation traits from the cattle QTLdb database. The nearest genes to the top SNP were CSF2 and IL3 (Table 6).

The most significant SNP in BTA6 region was Hapmap33451-BTC-060559 $\left(P\right.$-value $\left.=1.5 \times 10^{-7}\right)$. This SNP was between 2 candidate genes, $3 \mathrm{~kb}$ upstream of CSN2 and $16 \mathrm{~kb}$ downstream of CSN1S1. These 2 milk protein genes have been associated with milk protein production in dairy cattle. In this genomic region, 601 QTL related to milk protein and fertility traits were reported in the cattle QTLdb database.

Maternal Genetic Effects. In the maternal genome, a single association was detected on BTA4 $(51,146,972-51,726,432 \mathrm{bp})$ by ssGWAS (Figure 5). 


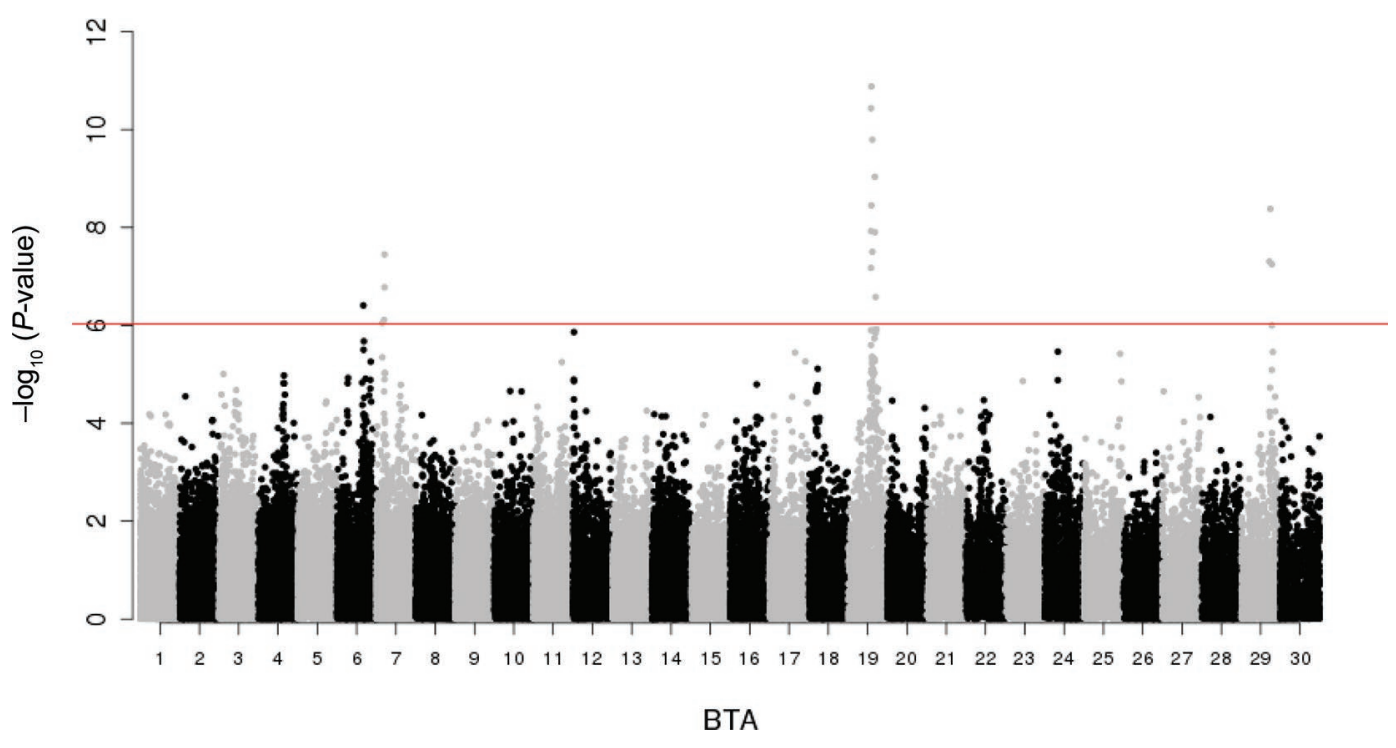

Figure 3. Manhattan plot for direct effects using mixed model genome-wide association study. Color version available online.

This region explained a substantial proportion of the maternal genetic variances with many SNP showing large allele substitution effects. However, this association was not detected by the traditional mixed model GWAS. In this region, the top SNP Hapmap549347rs29009770 (51,146,972 bp; minor allelic frequency = 0.47 ) explained $3.65 \%$ of maternal genetic variance. A good candidate gene, WNT2, was located $251 \mathrm{~kb}$ from the top associated SNP. Gene WNT2 is involved in the regulation of cell fate and patterning during embryogenesis and is essential for the development of placental vasculature. A total of 43 QTL in this region were reported to affect stillbirth, conception rate, and the interval from first to last insemination in the cattle QTLdb database.

\section{DISCUSSION}

\section{Nongenetic Effects}

All components included in the contemporary groups had significant effects on PAG levels, including herd, season, and ages of dam and embryo, showing the necessity of adjusting for these environmental fac- tors when modeling PAG levels. Herd was the most significant component, suggesting a strong nutritional effect on PAG levels, as most dairy farms used similar management practices. In humans, the effect of maternal nutrition on placental and fetal growth was known (Godfrey et al., 1996). In cattle, Sullivan et al. (2009) reported the effects of dietary protein during gestation on circulating indicators of placental function and fetal development in heifers (Sullivan et al., 2009). Therefore, PAG levels in milk could be an indicator of conceptus nutritional status. Across seasons, we observed an increased PAG level in warm weather, which could be related to maternal effects and homeostasis control (Supplemental Table S1; https://doi.org/10 $.3168 /$ jds.2018-14682). Bernabucci et al. (2015), studying heat stress in Holsteins, showed a lower level of milk components in summer (Bernabucci et al., 2015); however, they also observed larger values for IgG, serum albumin, and undefined proteins in summer than in winter or spring. Generally, levels of milk proteins produced outside of the mammary gland are increased on warm days, consistent with our results. As expected, the age of the embryo was positively associated with PAG levels (Patel et al., 1997). Barbato et al. (2017)

Table 6. Genomic regions and candidate genes associated with milk pregnancy-associated glycoproteins (PAG) levels

\begin{tabular}{lccll}
\hline Top SNP & Chromosome & Position & P-value & Genes nearby \\
\hline Hapmap33451-BTC-060559 & 6 & $87,176,472$ & $1.5 \times 10^{-7}$ & CSN2, CSN1S1 \\
ARS-BFGL-NGS-115315 & 7 & $23,697,106$ & $6.5 \times 10^{-8}$ & CSF2, IL3 \\
Hapmap39272-BTA-45334 & 19 & $38,018,129$ & $2.4 \times 10^{-11}$ & B4GALNT2, GNGT2, ABI3, PHOSPHO1 \\
ARS-BFGL-NGS-95362 & 29 & $38,300,709$ & $5.3 \times 10^{-10}$ & PAG2, PAG4, PAG5, PAG7, PAG10, PAG12, PAG14, \\
& & & PAG15, PAG18, PAG20, PAG21 \\
\hline
\end{tabular}




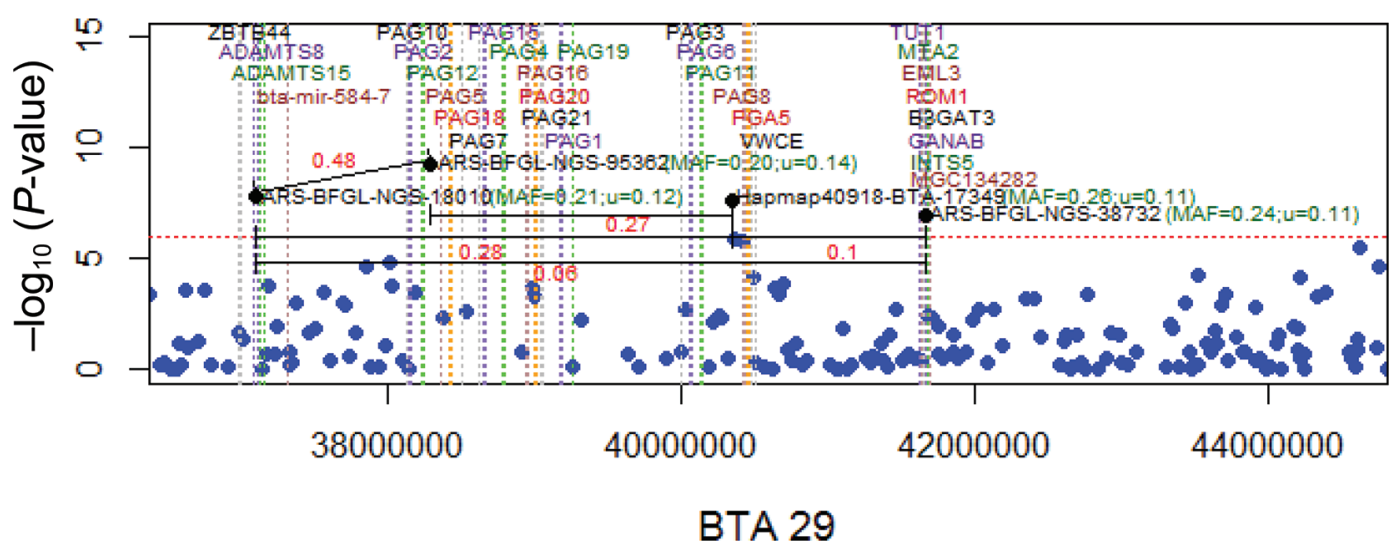

Figure 4. Regional association plot with genes around the top SNP (black dots). The bars and the numbers refer to linkage disequilibrium $\left(r^{2}\right)$ between these SNP. Color version available online.

observed progressively increased PAG expression until d 105 postinsemination, corresponding to the stage of development with greater placental growth in water buffalo (Barbato et al., 2017). As PAG is produced by the trophoblast, embryonic development and fetal growth are accompanied by the growth of placenta and, consequently, the increase of PAG production.

\section{Genetic Parameters}

Genetic effects on milk PAG levels contributed 27 to $37 \%$ (direct and maternal) of the phenotypic variance. A recent study of PAG expression in cows with retained placenta suggested a regulatory role of PAG in the release of bovine fetal membranes (Hooshmandabbasi et al., 2018). Our heritability estimate for the PAG direct effect was greater than those reported for retained placenta when only dams were used in the model $(0.08$; Hossein-Zadeh and Ardalan, 2011), but was similar to those studies that used sire-maternal grandsire models (0.22; Benedictus et al., 2013). Importantly, our study is one of the first to report the estimated heritability of a placenta trait by directly including embryos in the model, which should produce more accurate estimates of (co)variances. The estimated heritability for PAG was greater than that for fetal weight and lower than the heritability of fetal height when compared with human fetal traits in the second to third trimesters (Mook-Kanamori et al., 2012). In Holstein cattle, our estimated total heritability of PAG was lower than birth weight (Coffey et al., 2006), whereas the direct effect had a heritability similar to other dairy traits (VanRaden et al., 2004). These results suggest PAG levels to be a moderately heritable trait, and we can expect a selection response similar to other production traits in dairy cattle. Selection on PAG can be especially beneficial if it helps maintain pregnancy or correlates with other dairy traits, particularly adult traits.

The inclusion of a maternal effect in the model was adequate because it explained more than $11 \%$ of phenotypic variance. The estimated maternal heritability of PAG was similar to that of birth weight in beef cattle (MacNeil, 2005). Several studies have reported the effect of maternal growth factors on placental development, including IGF-1 and IGF-2, epidermal growth factor, platelet-derived growth factor, fibroblast growth factors 2 and 4, and members of the transforming growth factor $\beta$ superfamily (Forbes and Westwood, 2010). Our results suggest that more than $30 \%$ of the genetic variance was attributable to maternal resources, possibly from maternal growth factors, as PAG levels are related to placental formation. In addition, the heritability of maternal effects was consistent with that obtained for gestation length but greater than estimates for other fertility traits in Holsteins (VanRaden et al., 2004).

The use of genomic data substantially increased the estimated variance of direct effect $(57 \%)$, but the estimate for maternal effect remained the same. Compared with pedigree-based analysis, genomic data provided the best capture of the variability of the direct or embryo effect, which agreed with the improved accuracy from genomic evaluation (VanRaden et al., 2009). Thus, the genomic model that incorporates genotype information can be considered as the best for the genetic evaluation of PAG levels in milk. The estimated covariance between maternal and direct effects using this model is close to zero, even though the effects share almost half of the genome in common, suggesting that they are likely influenced by different genes and may be used for different selection objectives. 
$\mathbf{A}$

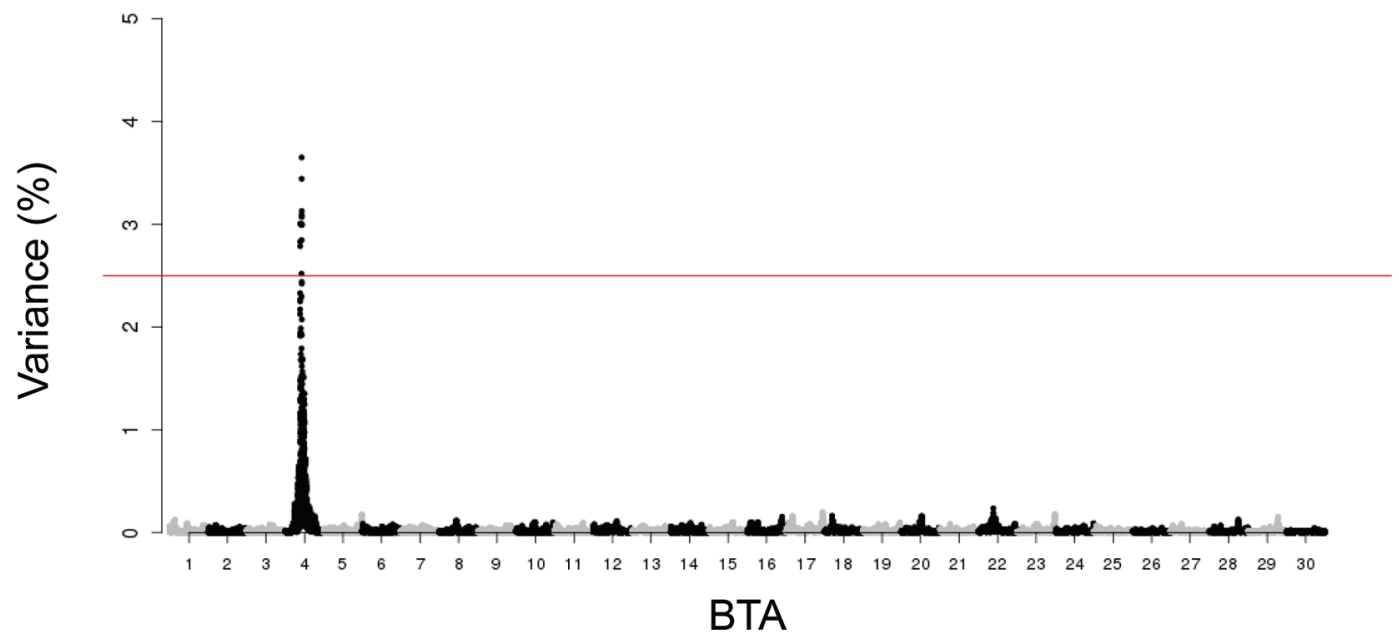

B

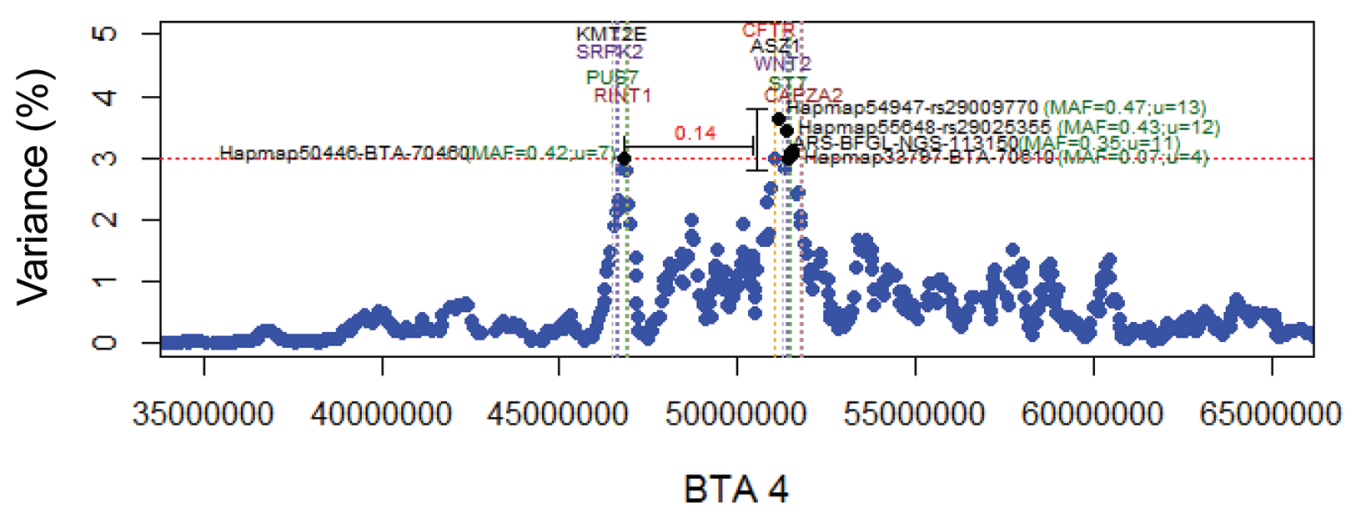

Figure 5. Genome-wide Manhattan (A) and regional (B) plots of genetic variance with genes around the top SNP (black dots). The bars and numbers refer to the average of linkage disequilibrium $\left(\mathrm{r}^{2}\right)$ surrounding the top SNP, Hapmap549347-rs29009770 (BTA4:51,146,972). Color version available online.

\section{Correlation with Economically Important Dairy Traits}

The estimated correlations were low to moderate between PAG levels and economically important dairy traits. The low correlation between PAG levels and direct breeding values of production and fertility traits suggest that these traits in the dams are less associated with PAG levels, which is inconsistent with previous literature reports. However, the estimated correlations were significantly different from zero for a few fertility traits, specifically positive for calving ease and stillbirth and negative for conception rates. The positive correlation indicates a beneficial relationship between PAG levels and fetal development. One possible explanation for the negative correlation between PAG and conception rates is that only pregnant cows were used for this correlation, whereas PAG data from nonpregnant cows were excluded. Mercadante et al. (2016) detected an association between plasma PAG concentrations and AI service number and parity (fertility trait), but no significant association for body score (Mercadante et al., 2016). They also reported that the cows with greater milk yield had increased plasma PAG concentrations, whereas López-Gatius et al. (2007) reported a significant negative association between milk production and PAG values when studying cow pregnancy until d 63 (LópezGatius et al., 2007). These inconsistent results indicated a poor inference on the effect of PAG levels on dairy traits. Our correlations between trait GEBV and maternal PAG effect could be more accurate, with low to moderate correlations observed for traits other than body conformations. In general, our estimated correlations between PAG (direct or maternal) and GEBV of economic traits had similar magnitudes of correlations with those estimated between Holstein traits groups, including production, fertility, and conformation traits (VanRaden and Cole, 2014). The placental and embryonic, fetal, or animal tissues may have different QTL 
with different effects, which may contribute to the low magnitude of genetic correlations between PAG levels and adult traits (Koukoura et al., 2012). Additionally, the effect of PAG on dam fertility traits could be better studied using direct phenotypic records of corresponding pregnancies rather than breeding values.

\section{GWAS in the Embryo Genome for Direct Genetic Effects}

The 2 most significant associations, on BTA 19 and 29, were detected by both GWAS approaches. Whereas the 2 GWAS methods in general produced consistent results, they used different criteria for detecting associations: ssGWAS considers variances explained by variants whereas the mixed model method uses statistical tests and $P$-values. Therefore, the top 2 regions have both statistical significance and large genetic variances explained in the Holstein population. Both BTA 6 and 7 associated regions had a significant effect on PAG production but did not explain large enough genetic variances.

The associated region on BTA 6 is within a casein gene cluster, including the CSN2, CSN1S1, and CSN1S2 genes. The HSTN gene is related to $\beta-\mathrm{CN}$ expression (Elsik et al., 2009). The top SNP was between 2 candidate genes, $3 \mathrm{~kb}$ upstream of CSN2 and $16 \mathrm{~kb}$ downstream of CSN1S1. These 2 milk protein genes have been associated with milk protein production in dairy cattle (Kucerova et al., 2006). Gene STATH encodes a salivary protein (statherin) that prevents precipitation of calcium phosphate. Many cattle QTL reported in this region are associated with the production of casein and other milk proteins. Although a functional link between PAG and this region is still unclear, this association is consistent with the moderate genetic correlation between PAG and protein yield (Table 5). Thus, it is possible that the PAG QTL in this region were affecting milk PAG levels through the regulation of milk proteins.

For the BTA 7 association, 3 candidate genes are located near the top SNP. Gene P4HA2 is related to collagen synthesis and reported as candidate gene for protein content in Holsteins (Cole et al., 2011), with differential expression in cattle mammary gland (Cui et al., 2014), and the CSF2 and IL3 genes encode, respectively, a cytokine and interleukin both related to immune response by stimulating the proliferation of defense cells. Gene CSF2 is differentially expressed depending on the sex of bovine embryos, and the expression of IL3 has been reported in mouse embryos (Robin et al., 2006; Siqueira and Hansen, 2016). Robin et al. (2006) also concluded that the IL3 gene has an important role as a survival factor for early hematopoietic stem cells in the mouse embryos (Robin et al., 2006). Whereas it is possible to relate PAG to immune modulation, there is another candidate gene, IGFBP 4, distal to the top SNP; IGFBP 4 has important functions on fetal growth (Popovici et al., 2001). The functional relationship between PAG and this genomic region is clearer with reported QTL for stillbirth $(23,275,158-23,275,189 \mathrm{bp})$. Interestingly, this region also has QTL associated with conformation traits, which may explain the observed genetic correlation between PAG levels and body conformations traits (Table 5).

The BTA 19 region had the most significant association and a window that explained the largest genetic variance $(37,699,961-38,018,129 \mathrm{bp})$. Six genes near the top SNP have effects related to cell processes. These genes are either involved with transcriptional modulation (SPOP, PBH, ZNF652) or encode G protein subunit (GNGT2), glucose-dependent insulinotropic polypeptide $(G I P)$, or a phosphatase involved in bone mineralization (PHOSPHO1). Although none of these genes have an apparent relationship with PAG production, some of them can influence the transcription of $P A G$ or some metabolic pathways of PAG production. Three QTL for gestation length have been reported for cattle in this region. The maternal and fetal effects on estrous cycle have been studied (Ehn et al., 2007). Although the fetal effect may be confounded with the placental effect, our results suggest that part of the genetic variance of gestation length may come from the placenta in addition to the fact maternal and fetal effects are commonly modeled through the sire (Eaglen et al., 2013).

The BTA 29 also had highly significant SNP and a window that explained large genetic variances. This region had a cluster of $P A G$ genes, suggesting a cisregulatory QTL on the expression of PAG protein. Specifically, the most associated SNP $(38,300,709 \mathrm{bp})$ was inside a $P A G$ gene that was not well annotated between PAG5 and PAG12. Thompson et al. (2012) reported differential expression in endometrium tissues for $P A G$ 2, PAG8, PAG11, and PAG12 in early pregnancy, whereas Streyl et al. (2012) reported different expression for PAG3, PAG5, PAG6, PAG7, PAG9, PAG15, PAG17, $P A G 18$, and $P A G 21$ in placentomes. Our study used mainly PAG records from early pregnancy, so PAG12 could be a candidate gene contributing to the PAG production variation. Several QTL in this region were reported to be related to milk protein percentage, indicating a genetic correlation of PAG and milk protein production. Another QTL at 37,751,599 to 37,751,639 bp was related to daughter pregnancy rate, suggesting 
a possible relationship between PAG production and pregnancy process.

\section{GWAS in the Dam Genome for Maternal Effects}

For maternal effects, only the ssGWAS method detected a signal on BTA4, possibly because this approach directly splits the maternal and direct genetic effects by SNP, different from the mixed model GWAS. The solution of maternal effect was used as dependent variable for mixed model GWAS analysis (Equation 2), but no maternal association signals were observed. Thus, the ssGWAS could be more powerful for GWAS of maternal effects our study. Two genes within the window $(51,146,972-51,726,432 \mathrm{bp})$ explained the largest genetic variance of maternal effect. The ASZ1 gene encodes a protein with a central role for spermatogenesis and is involved in germ cell maturation; WNT2 encodes signaling proteins involved in the regulation of cell fate and patterning during embryogenesis. Monkley et al. (1996) suggested that WNT2 is essential for development of placental vasculature in mice. Zhang et al. (2013), studying the expression of WNT2 in placenta, reported an association between the expression of WNT2 with normal and preeclampsia placenta. In cattle, this region $(51,655,230-51,655,270 \mathrm{bp})$ had a QTL related to maternal stillbirth. Probably, PAG expression QTL was related to different patterns of maternal vascularization of placenta, thus influencing the gestation health as well as PAG concentration in the maternal blood and milk. Gene WNT2 can be considered a candidate gene to explain the maternal effect on placenta development. Additionally, this region had 2 QTL reported for conception rate $(52,624,584-$ $52,690,928 \mathrm{bp})$ and the interval from first to last insemination $(52,669,435-52,690,928 \mathrm{bp})$, indicating a correlation between fertility and PAG maternal effect.

\section{CONCLUSIONS}

Moderate genetic control of PAG levels in milk exists, with 70 and $30 \%$ of genetic variances attributable to embryonic and maternal effects, respectively. The genetic correlation between PAG levels and economically important dairy traits was low in our preliminary analysis. From the embryonic genome, we detected a cis-regulating QTL of PAG in the PAG gene cluster and several trans-regulating QTL on BTA 6, 7, and 19. From the maternal genome, we also found a QTL of PAG expression on BTA 4, with WNT2 being a candidate gene related to placenta vascularization and gestation health. Due to the low correlation with conventional traits in our preliminary analysis, larger studies are need to fully evaluate the usefulness of milk PAG levels in the genetic evaluation of fetal growth and cow fertility.

\section{ACKNOWLEDGMENTS}

This research was supported in part by AFRI grant No. 2016-67015-24886 from the USDA NIFA (Washington, DC) and grant No. US-4997-17 from the US-Israel Binational Agricultural Research and Development Fund (Rishon LeZion, Israel). DJAS was also supported by São Paulo Research Foundation (FAPESP) research scholarship No. 2017/00462-5 and No. 2015/12396-1. JBC and DJN were also supported by appropriated projects 1265-31000-096-00, "Improving Genetic Predictions in Dairy Animals Using Phenotypic and Genomic Information," and 8042-31000-104-00, "Enhancing Genetic Merit of Ruminants Through Genome Selection and Analysis," of the Agricultural Research Service of the USDA, respectively. Mention of trade names or commercial products in this article is solely for the purpose of providing specific information and does not imply recommendation or endorsement by the USDA. The USDA is an equal opportunity provider and employer. The funders had no role in study design, data collection and analysis, decision to publish, or preparation of the manuscript.

\section{REFERENCES}

Aguilar, I., I. Misztal, D. Johnson, A. Legarra, S. Tsuruta, and T. Lawlor. 2010. Hot topic: A unified approach to utilize phenotypic, full pedigree, and genomic information for genetic evaluation of Holstein final score1. J. Dairy Sci. 93:743-752.

Albert, F. W., S. Treusch, A. H. Shockley, J. S. Bloom, and L. Kruglyak. 2014. Genetics of single-cell protein abundance variation in large yeast populations. Nature 506:494.

Barbato, O., L. Menchetti, N. Sousa, A. Malfatti, G. Brecchia, C. Canali, J. Beckers, and V. Barile. 2017. Pregnancy-associated glycoproteins (PAGs) concentrations in water buffaloes (Bubalus bubalis) during gestation and the postpartum period. Theriogenology $97: 73-77$.

Benedictus, L., A. Koets, F. Kuijpers, I. Joosten, P. van Eldik, and H. Heuven. 2013. Heritable and non-heritable genetic effects on retained placenta in Meuse-Rhine-Yssel cattle. Anim. Reprod. Sci. $137: 1-7$.

Bernabucci, U., L. Basiricò, P. Morera, D. Dipasquale, A. Vitali, F. P. Cappelli, and L. Calamari. 2015. Effect of summer season on milk protein fractions in Holstein cows. J. Dairy Sci. 98:1815-1827.

Bourdon, R. M. 2000. Understanding Animal Breeding. Vol. 2. Prentice Hall Upper Saddle River, NJ.

Coffey, M. P., J. Hickey, and S. Brotherstone. 2006. Genetic aspects of growth of Holstein-Friesian dairy cows from birth to maturity. J. Dairy Sci. 89:322-329.

Cole, J. B., G. R. Wiggans, L. Ma, T. S. Sonstegard, T. J. Lawlor, B. A. Crooker, C. P. Van Tassell, J. Yang, S. Wang, and L. K. Matukumalli. 2011. Genome-wide association analysis of thirty one production, health, reproduction and body conformation traits in contemporary US Holstein cows. BMC Genomics 12:408.

Commun, L., K. Velek, J.-B. Barbry, S. Pun, A. Rice, A. Mestek, C. Egli, and S. Leterme. 2016. Detection of pregnancy-associated gly- 
coproteins in milk and blood as a test for early pregnancy in dairy cows. J. Vet. Diagn. Invest. 28:207-213.

Cui, X., Y. Hou, S. Yang, Y. Xie, S. Zhang, Y. Zhang, Q. Zhang, X. Lu, G. E. Liu, and D. Sun. 2014. Transcriptional profiling of mammary gland in Holstein cows with extremely different milk protein and fat percentage using RNA sequencing. BMC Genomics 15:226.

Dosogne, H., A. Massart-Leen, and C. Burvenich. 2002. Immunological aspects of pregnancy-associated glycoproteins. Pages 295-305 in Biology of the Mammary Gland. Springer, Berlin, Germany.

Eaglen, S. A., M. Coffey, J. Woolliams, and E. Wall. 2013. Direct and maternal genetic relationships between calving ease, gestation length, milk production, fertility, type, and lifespan of HolsteinFriesian primiparous cows. J. Dairy Sci. 96:4015-4025.

Ehn, N. L., M. E. Cooper, K. Orr, M. Shi, M. K. Johnson, D. Caprau, J. Dagle, K. Steffen, K. Johnson, and M. L. Marazita. 2007. Evaluation of fetal and maternal genetic variation in the progesterone receptor gene for contributions to preterm birth. Pediatr. Res. 62:630.

Elsik, C. G., R. L. Tellam, and K. C. Worley. 2009. The genome sequence of taurine cattle: A window to ruminant biology and evolution. Science 324:522-528.

Forbes, K., and M. Westwood. 2010. Maternal growth factor regulation of human placental development and fetal growth. J. Endocrinol. 207:1-16.

Friedrich, M., and W. Holtz. 2010. Establishment of an ELISA for measuring bovine pregnancy-associated glycoprotein in serum or milk and its application for early pregnancy detection. Reprod. Domest. Anim. 45:142-146.

Gilad, Y., S. A. Rifkin, and J. K. Pritchard. 2008. Revealing the architecture of gene regulation: The promise of eQTL studies. Trends Genet. 24:408-415.

Godfrey, K., S. Robinson, D. Barker, C. Osmond, and V. Cox. 1996. Maternal nutrition in early and late pregnancy in relation to placental and fetal growth. BMJ 312:410.

Hannon, E., H. Spiers, J. Viana, R. Pidsley, J. Burrage, T. M. Murphy, C. Troakes, G. Turecki, M. C. O'donovan, and L. C. Schalkwyk. 2016. Methylation QTLs in the developing brain and their enrichment in schizophrenia risk loci. Nat. Neurosci. 19:48.

Hooshmandabbasi, R., H. Zerbe, S. Bauersachs, N. M. de Sousa, A. Boos, and K. Klisch. 2018. Pregnancy-associated glycoproteins in cows with retained fetal membranes. Theriogenology 105:158-163.

Hossein-Zadeh, N. G., and M. Ardalan. 2011. Bayesian estimates of genetic parameters for metritis, retained placenta, milk fever, and clinical mastitis in Holstein dairy cows via Gibbs sampling. Res. Vet. Sci. 90:146-149.

Hu, Z.-L., C. A. Park, X.-L. Wu, and J. M. Reecy. 2013. Animal QTLdb: An improved database tool for livestock animal QTL/association data dissemination in the post-genome era. Nucleic Acids Res. 41(D1):D871-D879.

Kinsella, R. J., A. Kähäri, S. Haider, J. Zamora, G. Proctor, G. Spudich, J. Almeida-King, D. Staines, P. Derwent, and A. Kerhornou. 2011. Ensembl BioMarts: A hub for data retrieval across taxonomic space. Database (Oxford) 2011:bar030.

Koukoura, O., S. Sifakis, and D. A. Spandidos. 2012. DNA methylation in the human placenta and fetal growth. Mol. Med. Rep. $5: 883-889$.

Kucerova, J., A. Matejicek, O. Jandurová, P. Sorensen, E. Nemcova, M. Stipkova, T. Kott, J. Bouska, and J. Frelich. 2006. Milk protein genes CSN1S1, CSN2, CSN3, LGB and their relation to genetic values of milk production parameters in Czech Fleckvieh. Czech J. Anim. Sci. 51:241.

López-Gatius, F., J. Garbayo, P. Santolaria, J. Yániz, A. Ayad, N. De Sousa, and J.-F. Beckers. 2007. Milk production correlates negatively with plasma levels of pregnancy-associated glycoprotein (PAG) during the early fetal period in high producing dairy cows with live fetuses. Domest. Anim. Endocrinol. 32:29-42.

MacNeil, M. D. 2005. Genetic evaluation of the ratio of calf weaning weight to cow weight 12 3. J. Anim. Sci. 83:794-802.

Mercadante, P. M., E. Ribeiro, C. Risco, and A. Ealy. 2016. Associations between pregnancy-associated glycoproteins and pregnancy outcomes, milk yield, parity, and clinical diseases in high-producing dairy cows. J. Dairy Sci. 99:3031-3040.

Mercadante, P. M., K. Waters, V. Mercadante, G. Lamb, M. Elzo, S. Johnson, D. Rae, J. Yelich, and A. Ealy. 2013. Subspecies differences in early fetal development and plasma pregnancy-associated glycoprotein concentrations in cattle. J. Anim. Sci. 91:3693-3701.

Misztal, I., S. Tsuruta, D. Lourenco, I. Aguilar, A. Legarra, and Z Vitezica. 2014. Manual for BLUPF90 Family of Programs. University of Georgia, Athens.

Monkley, S. J., S. J. Delaney, D. J. Pennisi, J. H. Christiansen, and B. J. Wainwright. 1996. Targeted disruption of the Wnt2 gene results in placentation defects. Development 122:3343-3353.

Mook-Kanamori, D. O., C. E. Van Beijsterveldt, E. A. Steegers, Y. S. Aulchenko, H. Raat, A. Hofman, P. H. Eilers, D. I. Boomsma, and V. W. Jaddoe. 2012. Heritability estimates of body size in fetal life and early childhood. PLoS One 7:e39901.

O'Connell, J. R. 2015. MMAP User Guide. Accessed Oct. 8, 2015 http://edn.som.umaryland.edu/mmap/index.php.

Patel, O. V., J. Sulon, J. F. Beckers, T. Takahashi, M. Hirako, N. Sasaki, and I. Domeki. 1997. Plasma bovine pregnancy-associated glycoprotein concentrations throughout gestation in relationship to fetal number in the cow. Eur. J. Endocrinol. 137:423-428.

Pinheiro, J. 2009. nlme: Linear and nonlinear mixed effects models. Accessed Feb. 20, 2018. http://cran.r-project.org/web/packages/ nlme/index.html.

Pohler, K. G., T. Geary, C. Johnson, J. Atkins, E. Jinks, D. Busch, J. Green, M. MacNeil, and M. Smith. 2013. Circulating bovine pregnancy associated glycoproteins are associated with late embryonic/fetal survival but not ovulatory follicle size in suckled beef cows. J. Anim. Sci. 91:4158-4167.

Popovici, R. M., M. Lu, S. Bhatia, G. Faessen, A. Giaccia, and L. Giudice. 2001. Hypoxia regulates insulin-like growth factor-binding protein 1 in human fetal hepatocytes in primary culture: suggestive molecular mechanisms for in utero fetal growth restriction caused by uteroplacental insufficiency. J. Clin. Endocrinol. Metab. $86: 2653-2659$.

Purcell, S., B. Neale, K. Todd-Brown, L. Thomas, M. A. Ferreira, D. Bender, J. Maller, P. Sklar, P. I. De Bakker, and M. J. Daly. 2007. PLINK: A tool set for whole-genome association and populationbased linkage analyses. Am. J. Hum. Genet. 81:559-575.

R Core Team. 2013. R: A language and environment for statistical computing. Accessed Feb. 20, 2018. https://www.r-project.org/.

Robin, C., K. Ottersbach, C. Durand, M. Peeters, L. Vanes, V. Tybulewicz, and E. Dzierzak. 2006. An unexpected role for IL-3 in the embryonic development of hematopoietic stem cells. Dev. Cell 11:171-180.

Roland, M. C. P., C. M. Friis, N. Voldner, K. Godang, J. Bollerslev, G. Haugen, and T. Henriksen. 2012. Fetal growth versus birthweight: The role of placenta versus other determinants. PLoS One $7: \mathrm{e} 39324$

Siqueira, L. G., and P. J. Hansen. 2016. Sex differences in response of the bovine embryo to colony-stimulating factor 2 . Reproduction 152:645-654

Streyl, D., R. Kenngott, N. Herbach, R. Wanke, H. Blum, F. Sinowatz, E. Wolf, H. Zerbe, and S. Bauersachs. 2012. Gene expression profiling of bovine peripartal placentomes: detection of molecular pathways potentially involved in the release of foetal membranes. Reproduction 143:85-105.

Sullivan, T. M., G. Micke, R. Magalhaes, G. Martin, C. Wallace, J. Green, and V. Perry. 2009. Dietary protein during gestation affects circulating indicators of placental function and fetal development in heifers. Placenta 30:348-354.

Telugu, B. P. V., M. O. Palmier, S. R. Van Doren, and J. A. Green. 2010. An examination of the proteolytic activity for bovine pregnancy-associated glycoproteins 2 and 12. Biol. Chem. 391:259-270.

Thompson, I. M., R. Cerri, I. Kim, A. Ealy, P. Hansen, C. Staples, and W. Thatcher. 2012. Effects of lactation and pregnancy on metabolic and hormonal responses and expression of selected conceptus and endometrial genes of Holstein dairy cattle. J. Dairy Sci. 95:5645-5656. 
VanRaden, P., and J. Cole. 2014. Net merit as a measure of lifetime profit: 2014 revision. Animal Improvement Programs Laboratory, ARS-USDA, Beltsville, MD.

VanRaden, P. M., A. Sanders, M. Tooker, R. Miller, H. Norman, M. Kuhn, and G. Wiggans. 2004. Development of a national genetic evaluation for cow fertility. J. Dairy Sci. 87:2285-2292.

VanRaden, P. M., C. Van Tassell, G. Wiggans, T. Sonstegard, R. Schnabel, J. Taylor, and F. Schenkel. 2009. Invited review: Reliability of genomic predictions for North American Holstein bulls. J. Dairy Sci. 92:16-24.

VanRaden, P. M. 2008. Efficient methods to compute genomic predictions. J. Dairy Sci. 91:4414-4423.

VanRaden, P. M., J. R. O'Connell, G. R. Wiggans, and K. A. Weigel. 2011. Genomic evaluations with many more genotypes. Genet. Sel. Evol. 43:10.

Wang, H., I. Misztal, I. Aguilar, A. Legarra, and W. Muir. 2012. Genome-wide association mapping including phenotypes from relatives without genotypes. Genet. Res. (Camb.) 94:73-83.

Welter, D., J. MacArthur, J. Morales, T. Burdett, P. Hall, H. Junkins, A. Klemm, P. Flicek, T. Manolio, and L. Hindorff. 2014. The NH-
GRI GWAS Catalog, a curated resource of SNP-trait associations. Nucleic Acids Res. 42(D1):D1001-D1006.

Wu, G., F. Bazer, J. Wallace, and T. Spencer. 2006. Board-invited review: Intrauterine growth retardation: Implications for the animal sciences1. J. Anim. Sci. 84:2316-2337.

Zhang, Z., L. Zhang, L. Zhang, L. Jia, P. Wang, and Y. Gao. 2013. Association of Wnt2 and sFRP4 expression in the third trimester placenta in women with severe preeclampsia. Reprod. Sci. 20:981-989.

Zimin, A. V., A. L. Delcher, L. Florea, D. R. Kelley, M. C. Schatz, D. Puiu, F. Hanrahan, G. Pertea, C. P. Van Tassell, and T. S. Sonstegard. 2009. A whole-genome assembly of the domestic cow, Bos taurus. Genome Biol. 10:R42.

Zoli, A. P., P. Demez, J.-F. Beckers, M. Reznik, and A. Beckers. 1992a. Light and electron microscopic immunolocalization of bovine pregnancy-associated glycoprotein in the bovine placentome. Biol. Reprod. 46:623-629.

Zoli, A. P., L. A. Guilbault, P. Delahaut, W. B. Ortiz, and J.-F. Beckers. 1992b. Radioimmunoassay of a bovine pregnancy-associated glycoprotein in serum: Its application for pregnancy diagnosis. Biol. Reprod. 46:83-92. 